\title{
They are analyzing us: Our own survey is needed
}

\author{
Kun Hwang
}

Ethics Editor, Archives of Plastic Surgery

Department of Plastic Surgery, Inha University School of Medicine, Incheon, Korea

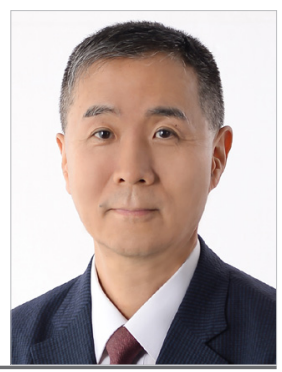

When I searched for a paper written by a plastic surgeon colleague of mine, I found that it had been cited four times [1]. Interestingly, one of the citations was from a paper that had been published in a journal in the field of management, not in a medical journal [2].

Because the title contained the intriguing words "cosmetic surgery" and "Seoul," I read the linked article. It was written by researchers in the fields of business and accounting from Malaysia and China, and the journal was published in the United States.

In order to collect market data on women's willingness to undergo cosmetic surgery in Seoul, the authors interviewed 400 women aged 19-40 years in Seoul using a self-administered questionnaire. These researchers in the fields of business and accounting used the theory of reasoned action, which analyzes factors such as attitudes, subjective norms (celebrities and the media), psychological attributes (social status and self-esteem) that influence patients' intention to undergo cosmetic surgery. They found generally positive attitudes towards cosmetic surgery among women living in Seoul, with favorable intentions towards cosmetic surgery, as manifested by the belief among Korean women that undergoing cosmetic surgery is the most effective way to improve their appearance and social status. Their results revealed that celebrities and the media played an important role in influencing women to undergo surgery.

The authors approached this topic from the perspective of marketing and management, and suggested that their results provided important information for designing effective strategies to advertise and promote cosmetic surgery. They also discussed psychological attributes, such as self-esteem and social status.
Reading this article, I was surprised that researchers in the field of business and accounting wrote this paper and that they were interested in cosmetic surgery marketing in Seoul. Although there are only about 51 million Koreans living in South Korea and 7.4 million Koreans living outside of the Korean Peninsula, accounting for roughly $1 \%$ of the world population [3], the authors were clearly aware that South Korea is ranked third in the world in the number of cosmetic procedures, with $1,156,000$ Koreans undergoing such procedures in 2015 [4], and the Korean cosmetic surgery market has a $24 \%$ market share of the total world market [5].

I think that the authors of this article regard the Seoul cosmetic surgery market as a wide-open field (blue ocean) for future business initiatives.

The Korean Society of Plastic and Reconstructive Surgeons (KSPRS) has been gathering data from all training hospitals for many years. At any training hospital, we must report daily information on the operations performed and the number of patients in our department. However, I have not seen any articles based on the prospective data collected by our society.

As the authors in the field of business and accounting suggested, additional research is needed to determine patients' satisfaction with non-core and post-cosmetic surgery services (aftersales services), such as the doctor's skills and knowledge, the environment of the clinic, and other factors that collectively define the total or augmented product.

The KSPRS has recently been making efforts to internationalize itself as a society [6]. We, as members of the KSPRS, should have a prospective analysis of our market before our possible ri- 
vals. We should analyze the market ourselves, instead of letting further surveys be done by marketing managers from countries that compete with us. For this, a survey supported by the Korean Society of Aesthetic Plastic Surgeons of the KSPRS is needed. Remember that our city, Seoul, is the "center of cosmetic surgery."

\section{NOTES}

\section{Conflict of interest}

No potential conflict of interest relevant to this article was reported.

\section{ORCID}

Kun Hwang https://orcid.org/0000-0002-1994-2538

\section{REFERENCES}

1. Choi J. Cosmetic surgery: is it science or art? Arch Plast Surg 2015;42:672-4.

2. Teng PK, Ling TJ, Seng KW. Propensity to undergo cosmetic surgery and services in Seoul. Int J Community Develop
Manag Stud 2019;3:1-16.

3. Chang DW. Plastic Surgeons of Korean Heritage: why it matters to me. Arch Plast Surg 2019;46:1-2.

4. International Society of Aesthetic Plastic Surgeons (ISAPS). ISAPS international survey on aesthetic/cosmetic procedures performed in 2015 [Internet]. Hanover, NH: ISAPS; c2019 [cited 2019 Jul 15]. Available from: https://www.isaps.org/ wp-content/uploads/2017/10/2016-ISAPS-Results-1.pdf.

5. Seoul Touch Up. Korean plastic surgery statistics [Internet]. Seoul: Seoul Touch Up; c2012 [cited 2019 Jul 15]. Available from: https://www.seoultouchup.com/korean-plastic-surgery-statistics/.

6. Kim KS. Into a global future with our members to serve the people. Arch Plast Surg 2019;46:99-101.

Correspondence: Kun Hwang

Department of Plastic Surgery, Inha University School of Medicine, 27 Inhang-ro, Jung-gu, Incheon 22332, Korea

Tel: +82-32-890-3514, Fax: +82-32-890-2918, E-mail: jokerhg@inha.ac.kr

Received: July 15, $2019 \bullet$ Revised: August 12, $2019 \bullet$ Accepted: August 13, 2019

pISSN: 2234-6163 • elSSN: 2234-6171

https://doi.org/10.5999/aps.2019.00899 • Arch Plast Surg 2019;46:397-398 